NBER WORKING PAPER SERIES

\title{
PUBLIC OR PRIVATE PRODUCTION OF FOOD SAFETY: WHAT DO U.S. CONSUMERS WANT?
}

\author{
V. Kerry Smith \\ Carol Mansfield \\ Aaron Strong \\ Working Paper 14287 \\ http://www.nber.org/papers/w14287 \\ NATIONAL BUREAU OF ECONOMIC RESEARCH \\ 1050 Massachusetts Avenue \\ Cambridge, MA 02138 \\ August 2008
}

This research was completed when the third author was a Postdoctoral Fellow, in CEESP, Arizona State University. Thanks are due F. Reed Johnson for assistance with the development of the experimental design for the survey, to Laurel Clayton, Eric Moore, Jonathan Eyer, and Garth Baughman for excellent research assistance and comments and to Richard Laborin for assistance in preparing several drafts of this manuscript. The research was supported by the United States Department of Homeland Security through the Center for Risk and Economic Analysis of Terrorism Events (CREATE) under grant numbers 2007-ST-061-000001 and DE-AC05-76RL01830. However, any opinions, findings, and conclusions or recommendations in this document are those of the authors and do not necessarily reflect views of the United States Department of Homeland Security. The views expressed herein are those of the author(s) and do not necessarily reflect the views of the National Bureau of Economic Research.

NBER working papers are circulated for discussion and comment purposes. They have not been peerreviewed or been subject to the review by the NBER Board of Directors that accompanies official NBER publications.

(C) 2008 by V. Kerry Smith, Carol Mansfield, and Aaron Strong. All rights reserved. Short sections of text, not to exceed two paragraphs, may be quoted without explicit permission provided that full credit, including $\odot$ notice, is given to the source. 
Public or Private Production of Food Safety: What Do U.S. Consumers Want?

V. Kerry Smith, Carol Mansfield, and Aaron Strong

NBER Working Paper No. 14287

August 2008

JEL No. H42,Q18

\begin{abstract}
$\underline{\text { ABSTRACT }}$
This paper reports estimates of consumers' preferences for plans to improve food safety. The plans are distinguished based on whether they address the ex ante risk of food borne illness or the ex post effects of the illness. They are also distinguished based on whether they focus on a public good -- reducing risk of illness for all consumers or allowing individual households to reduce their private risks of contracting a food borne pathogen. Based on a National Survey conducted in 2007 using the Knowledge Network internet panel our findings indicate consumers favor ex ante risk reductions and are willing to pay approximately $\$ 250$ annually to reduce the risk of food borne illness. Moreover, they prefer private to public approaches and would not support efforts to reduce the severity of cases of illness over risk reductions.
\end{abstract}

V. Kerry Smith

Department of Economics

W.P. Carey School of Business

P.O. Box 873806

Arizona State University

Tempe, AZ 85287-3806

and NBER

kerry.smith@asu.edu

Carol Mansfield

RTI International

3040 Cornwallis Rd.

PO Box 12194

Research Triangle Park, NC 27709

carolm@rti.org
Aaron Strong

2023 Keystone Ranch Rd.

Keystone, Colorado 80435

strongaa@yahoo.com 


\title{
$8 / 20 / 2008$
}

\section{Public or Private Production of Food Safety: What Do U.S. Consumers Want?}

\author{
V. Kerry Smith, Carol Mansfield, and Aaron Strong*
}

\section{Introduction}

Popular descriptions of the U.S. food safety system generally suggest it is "broken." ${ }^{1}$ Following the recent outbreak of salmonella attributed to tomatoes and more recently various types of jalapeno peppers, the Secretary of Health and Human Services announced a new budget request that would accelerate the implementation of joint strategies for improving food safety outlined in November 2007 as part of the Food Protection Plan and the Action Plan for Import Safety ${ }^{2}$. This latest increase would boost the Food and Drug Administration's (FDA) budget by 17.8\% (from FY2008), adding new inspectors as well as efforts to assure compliance with FDA requirements for high risk foreign and domestic food

\footnotetext{
* W. P. Carey Professor of Economics, Arizona State University, University Fellow Resources for the Future, and Research Associate, National Bureau of Economic Research; Senior Economist, RTI International; and Assistant Professor, Department of Economics and Finance, University of Wyoming respectively. This research was completed when the third author was a Postdoctoral Fellow, in CEESP, Arizona State University. Thanks are due F. Reed Johnson for assistance with the development of the experimental design for the survey, to Laurel Clayton, Eric Moore, Jonathan Eyer, and Garth Baughman for excellent research assistance and comments and to Richard Laborin for assistance in preparing several drafts of this manuscript. The research was supported by the United States Department of Homeland Security through the Center for Risk and Economic Analysis of Terrorism Events (CREATE) under grant numbers 2007-ST-061-000001 and DE-AC05-76RL01830. However, any opinions, findings, and conclusions or recommendations in this document are those of the authors and do not necessarily reflect views of the United States Department of Homeland Security.

${ }^{1}$ Both popular press accounts and attitude surveys confirm these attitudes. For example in June 2008, USA Today reports a Deloitte survey of 1,110 consumers on April 21 that indicated 76\% reported that compared with five years ago they were more concerned about the food they ate.

${ }^{2}$ The discussion of papers came after warning about tomatoes and the budget requests. see New York Times, "Warning on Tomatoes Is Withdrawn" 7/18/2008 and "Tainted jalapeno found in Texas" USA Today 7/22/2008.
} 
sources. ${ }^{3}$ Any public initiative of this sort is composed of a set of new rules and expenditures seeking to meet specific objectives, in this case improvements in food safety. However, there are no guarantees. The policies are best treated as plans to enhance food safety not assured improvements.

This paper reports the results of a national survey that evaluates what consumers would select if they had the opportunity to vote for one of three "plans" to improve food safety. Two of the three plans reduce the risk of food borne illness and one focuses on the severity of each case of illness. The three plans were : (1) to expand the current FDA inspection system (i.e. the one in existence before the 2007 plans), (2) to offer a product allowing households to test for pathogens on food, and thus avoid using contaminated foods or (3) to provide a medicine to reduce the severity of food borne illnesses.

In general, respondents to the survey conducted between the end of August and September, 2007 , have an annual willingness to pay of approximately $\$ 250$ for either the plan to increase FDA inspectors or the one offering a test kit for pathogens on food that households can purchase at a subsidized price. ${ }^{4}$ Both of these alternatives seek to reduce the risk of food borne illness. One is a public good in the sense that all consumers experience the risk reduction and the other is a private approach to reduce risk, relying on households purchasing and using the test kit to detect pathogens. The estimated economic values for these two alternatives are not significantly different. However, if we consider the added cost of purchasing the private test kits, in addition to the increase in income taxes to support either initiative, (using the average annual expenditures) households have a significantly higher economic value for the private alternative offering the home test kit for food borne pathogens. In addition our results clearly suggest consumers favor an ex ante focus on risk reduction; valuations for

\footnotetext{
${ }^{3}$ In the June 9, 2008, U.S. Department of Health and Human Services news release (http://www.hhs.gov/news/press/2008pres/06) the details of the plan were outlined. The specific focus was to improve import safety with 1,000 more proposed foreign inspections of food and medical product facilities and 1,000 more domestic inspections. Other steps include: accrediting trusted sources and allowing them expedited entry, modernizing information infrastructure, and introducing preventive controls for high risk foods. ${ }^{4}$ The estimates for the marginal willingness to pay are derived using a sample restricted to include respondents who understood the graphical presentation of risk and who responded with a 5 or greater that on a scale of 1 to 10 gauging the likelihood their responses would influence policy. The specific estimates are reported in column 3 of Table 5 below.
} 
both the public plan for increased inspection and the plan for home testing dominate the value of the proposed ex post strategy of medication to reduce the severity of cases of food borne illnesses at a subsidized price.

Our research design, findings, and their implications are presented in the next three sections. Section II begins with a discussion of the recent gloomy prognosis offered by Shogren and Stamlund [2007] for efforts to use consumers' food selections to evaluate the tradeoffs they would make to reduce risks of food borne illness. Their findings along with other recent research provide the background for the design of our stated preference survey. In the second half of this section, we outline the questions, experimental design, and survey format. In the third section, we discuss the estimates of choice models for our proposed plans to enhance food safety. We report estimates for the marginal willingness to pay for the plans and evaluate how the attributes of the plans and the characteristics of the respondents influence their choices. The last section summarizes our conclusions and discusses their implications for the current debate about how to enhance the security of the U.S. food supply.

\section{Evaluating Food Safety Policies: Context, Model, and Conjoint Survey}

\section{A. $\quad$ Context}

The Shogren and Stamland (2007) analysis is part of a larger study these authors conducted using the Knowledge Networks web panel. As part of one of the study, respondents were asked about their health status, behavior related to food safety risk, and risk perceptions. In the analysis, they found that measures of health status based on a variety of factual questions and measures of food safety related behavior were internally consistent. The health indices were correlated with other health measures and the indices of risk-related behaviors were correlated with other risk behavior measures. However, self-reported behavior did not correlate well with measures of each respondent's health status. Second, personal risk perception measures were uncorrelated with other variables, such as 
health status and risk behaviors. Finally, there was a correlation that the authors describe as "too high" between risk reduction behaviors for preparing beef, pork, and chicken. That is, their survey respondents described averting behaviors such as washing hands and utensils as effective in reducing risks of foodborne illness for beef, pork, and chicken, yet there was no correlation between their actual use of these behaviors and their reported perceptions of risks they face of food borne illness. Based on the correlation patterns, Shogren and Stamland conclude that reported food preparation behaviors that we would ordinarily assume were intended to reduce risks contain poor information about how people perceive food safety risks and respond to them. Their relative judgment stems from the failure of the respondents to satisfy the external consistency checks between these behaviors and different wordings for similar decisions.

During pre-testing of our survey, we also found that focus group participants sometimes had difficulties similar to what Shogren and Stamlund describe in "linking" personal behaviors to reductions in their stated risk perceptions. The issues posed were not confined to food borne illness. The participants explained the seeming contradictions between their willingness to take different actions and their perceptions of risk with statements noting that their personal actions were likely to be ineffective or that the issues we raised were problems that should be a public responsibility. When we assigned the individuals with the property rights to high risk situations, they countered that the risks were a public, not a private responsibility. In part, the results also reflect our failure to adequately describe the proposed private actions in a way respondents were willing to accept or to explain how the private actions were intended to work along with public actions to address each issue.

The recent Hammitt and Haninger [2007] study estimating the value of reductions in illness and mortality from food borne pathgens may face similar problems. ${ }^{5}$ Respondents were presented risk

\footnotetext{
${ }^{5}$ Without access to the specific text of their survey questionnaire, it is difficult to determine the level of detail used in presenting the choice questions. Their paper was a short summary of the research findings. The authors do not
} 
reductions produced by a stringent safety program that they were told did not use chemicals or irradiation to accomplish this reduction. Their proposed public actions vary in the size of the reduction in the probability of illness, the severity and duration of illness from food borne pathogens, the conditional probability of mortality, and the type of food that is associated with the risks. The results confirm a statistically significant and consistent relationship between choices made by the respondents and the size of the risk reduction but indicate there was little response to either the severity or the duration of typical cases of illness. Finally, the estimated willingness to pay in order to avoid statistical cases of illness is approximately an order of magnitude greater than estimates from the primary earlier study (by Hayes et. al. [1995]) for comparable risk changes. Moreover, Hammitt and Haninger's measures not only exceed the estimates from other studies but are dramatically larger (in real terms) than estimates of unit values routinely used for most types of short term illnesses in environmental benefit cost assessments. ${ }^{6}$

There is a reasonably large literature suggesting that it is difficult to explain risk reductions in a stated choice survey. The Shogren and Stamland results imply that the tangible nature of food preparation as a part of most households everyday activities does not necessarily increase the feasibility of measuring economic values for reductions in the risk of food borne illness. Our results suggest that respondents need to be presented with choices that connect what is offered to them in the survey and the change in risk or attributes of food in a tangible way. Saying risk reductions or health improvements will take place doesn't convince them. Describing the mechanism that accomplishes the changes may but this needs to be evaluated within pretest activities. Thus, our results parallel the contingent

report the use of specific follow up questions to gauge whether respondents believed the outcomes would actually be realized.

${ }^{6}$ For example the First Prospective Analysis conducted by EPA reports unit values for morbidity effects related to air pollution ranging from $\$ 5.30$ to $\$ 83$ per day for respirator effects (at the low end) and work loss days at the high end. Cases of emergency room visits are estimated to involve a \$194 loss per case. Only hospital admissions for cardiovascular cases approach the estimates reported by Hammitt and Haninger. The EPA estimates are in 1990 dollars. Even with adjustments for cost of living differences, most are dramatically lower than Hammitt and Haninger's results for food borne illness. See Table 6-1 in U.S. Environmental Protection Agency [1999]. 
valuation research undertaken for large natural resource damage assessments (see Carson et. al [2003]. In these cases what was offered to respondents was an intermediate action or what we have labeled a "plan" to realize a change in an object of choice. Our conjoint survey expands this logic and offers several different plans as choice alternatives. As with the earlier CV research there remains a challenge in establishing connections between the plans and changes in the attributes or resources of interest (see Smith [1997]).

\section{B. $\quad$ Model}

Based on this past experience our analysis was designed for a survey using a conjoint/discrete choice framework with "labeled" choice alternatives. Each choice alternative is a specific plan to address food safety by either reducing the risk of experiencing a food borne illness or the severity of a case of food borne illness. The size of the risk change and reductions in severity vary across choice alternatives as do their cost and (in the case of one type of plan) the time required to use the proposed approach to reduce risk. However, the variation in these attributes is constrained to be consistent with the logical structure of each plan. In the text describing each plan, we emphasize what the plan can and cannot do. For example, a proposed medication taken at the first signs of the onset of a case of food poisoning cannot reduce the risk of contracting the disease. The test kit and increased inspections do not reduce the severity of the case, only the risk that the respondent contracts it. As a result, the plans are not described by the same set of attributes.

This approach is somewhat different than most applications of conjoint stated preference methods where, as Holmes and Adamowicz [2003] suggest for environmental applications, the objective is to estimate the values of "a technically divisible set of attributes of an environmental good." As these 
authors are careful to note, the logic maintains that commodities are demanded for their attributes and people perceive the same attributes in about the same ways. ${ }^{7}$

In this survey, we are interested in how respondents view a set of very different plans to address the problem of food borne illness. Because the plans we developed do not have a single common set of attributes, our strategy combines the approaches of contingent valuation studies and conjoint analysis. Looking at the insights developed from debates in the early 1990s arising from the use of stated preference surveys for damage assessments, the contingent valuation surveys that were widely perceived to be successful, such as the 1991 study of the Exxon Valdez oil spill (see Carson and Hanemann [2005]), presented the object of choice as a plan to avoid future damages. ${ }^{8}$ In a similar way, we present plans to avoid future illnesses, but unlike a traditional contingent value survey the plans do contain attributes and the attributes vary according to the experimental design strategy used in conjoint surveys.

A focus on plans implies the modeling of choices relies first on a simple discrete choice random utility model specified in terms of the cost (money and where relevant time) and the alternative specific constants for each plan. Our most detailed specification includes the varying risk and severity attributes interacted with respondent characteristics. ${ }^{9}$ The effects of these attributes cannot be separately

\footnotetext{
${ }^{7}$ Describing goods and services by their attributes to estimate consumer preferences, as conjoint surveys do, relies on several assumptions. The first, as noted in the text, is the association of the attribute vector with choice alternatives. In practice consumers select commodities that differ in characteristics and cannot necessarily repackage attributes any way they wish. A discrete set of alternative bundles are available.

A second set of issues that arise in these models concerns how people perceive the attributes and whether there is heterogeneity in the importance they place on different attributes. These issues arise in the specification of mixed logit models. Since our framework offers 3 distinct plans to improve food safety that do not all contain the same attributes, we have not considered these other important elements due to the perceptions and valuation of individual attributes by different people. See Train [2003] for discussion of the econometric implications of these assumptions.

${ }^{8}$ We do not formulate the model in expected utility terms because consumers are assumed to select plans on bundles of risk reductions and other attributes. One plan, the medicine to reduce severity of illness, does not offer an ex ante risk reduction from baseline conditions.

${ }^{9}$ We also include the inverse Mills terms in interaction form with the time stated as required for the plan to use home tests to detect food borne pathogens.
} 
estimated because the "plan consistency constraints" create collinearity between them and the alternative specific constants. Moreover, a model based solely on attributes is misleading because linear or even simple non-linear specifications do not necessarily capture the constraints imposed in the design.

Equation (1) presents our simple model. We treat the risk of incurring food borne illness as an attribute evaluated differently by different types of individuals. ${ }^{10}$

$$
V_{i j}=v\left(y_{i}-c_{i j}, \bar{a}, \bar{a} \times Z_{i}, \bar{A}_{j} \times \bar{Z}_{i}\right)+\varepsilon_{i j}
$$

$V_{i j}$ designates the utility individual $i$ realizes from selecting choice alternative $j_{i}, y_{i}$ designates income from individual $\mathrm{I}, \mathrm{c}_{\mathrm{ij}}$ corresponds to the cost presented to individual i for choice alternative $\mathrm{j}$, $\bar{a}$ corresponds to the vector of alternative specific constants relevant to each person based on the choice panels he received, $\bar{A}_{j}$ represents a vector of attributes for choice alternative $\mathrm{j}, \bar{Z}_{j}$ designates characteristics of each respondent that are hypothesized to influence choices, and $\varepsilon_{i j}$ is assumed to be i.i.d. and to follow a type I extreme value distribution. The two terms $\bar{a} \times \bar{Z}_{i}$ and $\bar{A}_{j} \times \bar{Z}_{i}$ offer a short hand for specifications that include respondent attributes interacted with alternative specific constants for the plans as well as between plan attributes and respondent characteristics. For a respondent's characteristics to be included in simple RUM specifications they must be interacted with attributes of the choice alternatives or with an alternative specific constant.

We also investigated model specifications in terms of the attributes of the plans alone. They confirm people's preferences for risk reductions over an ex post focus of the severity of cases of food borne illness. The design restrictions linking risk changes and time changes to one plan, severity changes to another, and risk change alone to the third imply that simple interpretation of the individual estimated coefficients in this specification would be incorrect.

${ }^{10}$ The structure of our choice experiment and sample size suggest there is little advantage in a random coefficient or mixed logit specification. 


\section{Design of Choice Alternatives}

Our stated choice questions are based on three alternative plans to protect food safety. The plans were developed after pretesting a wide array of strategies for describing the possibility of health threats in four separate focus groups conducted in Phoenix and New York City. In each city, we conducted two focus groups that were distinguished based on whether participants made less or more than the median income for the households in each location. While each pairing received the same information, the New York groups received information materials that were revised to take account of the comments we learned from the Phoenix sessions.

Threats were presented initially as evolving stories of contamination or in terms of some specific source for a contaminant. We found participants were willing to acknowledge the plausibility of the threats, but did not accept the proposed policies as workable. This was especially true if the policy required responses by ordinary households. A pre-test survey conducted using the Knowledge Networks web panel in mid- July 2007 with 170 respondents evaluated further revisions of the sources of the illness and the severity of cases of food borne illness. The results from the focus groups and the pretest suggested respondents would be likely to select the status quo over a wide range of risks, levels for the illness severity, and costs for plans to address the problem. These outcomes seemed to arise even with individuals who acknowledged the severity of the problem of food borne illness. The key considerations in respondents' willingness to consider alternatives aside from the status quo were clear explanations of the status quo conditions and descriptions of plans to improve upon that situation that seemed plausible and potentially effective.

To allow for the possibility that our adjustment to framing and design of the choice alternatives would be ineffective in convincing respondents that these were plausible and effective alternatives, half of the respondents to the final survey were assigned to the conventional format for a conjoint choice involving two plans to deal with food borne illness and a status quo or no change option. The other half 
of the respondents were first asked "forced choice" questions. That is they were asked to select between two plans based on the assumption that a decision had already been made by the government to undertake a public protection effort with a pre-defined cost per household in increased taxes. After selecting between the two alternatives, respondents were then asked whether they would vote for their preferred plan at the pre-defined tax cost. Based on the survey results, we do not observe an excessive number of status quo responses, indicating that the presentation of choice alternatives was perceived as salient and credible. So we confine our analysis to the set of respondents who answered the conventional conjoint that included the status quo option.

Two of the plans represent ex ante responses that influence the probability of illnesses. They vary depending on whether the individual undertakes the averting activity himself or the protection arises as a public good available to all households thru greater food inspection. The third plan focuses on the severity of cases of food borne related illness. Figure 1a provides the text used to describe all three plans:

- the ex ante private plan-a home test kit for food borne contaminants;

- an ex ante plan to reduce risk by hiring more food inspectors;

- an ex post option that offers a medicine that influences the severity of the illness once it is contracted.

All plans suggested that there would be an additional cost, added to each person's federal income taxes, for development and implementation whichever plan was selected. In addition, for the private options (i.e. the test kit and the medicine), there was an additional cost associated with purchasing the test kit and medication. These costs were described in monthly and annual terms (assuming each respondent would purchase them as prescribed). In addition, the test kit was described as involving some added time in food preparation each time the kit was used. This added time requirement was not a part of the other plans. Figure $1 \mathrm{~b}$ reproduces a representative choice panel from this survey. 
The presentation of risk as an attribute of the choice alternatives used the Corso et.al. [2001] strategy for presenting risks - a box with 1,000 squares. A fraction of the squares were colored in red to designate the incidence of an event with the proportion of colored squares representing the probability. To gauge respondents' understanding of the graphical presentation we asked each person to compare the relative risk associated with two different probabilities using the boxes with colored panels to indicate graphically their relative frequencies of an event. This process asked them to compare the depiction of 270 in 1,000 versus 3 in 1,000 risks and then to evaluate whether the box with 3 in 1,000 was a higher or lower risk than the one with 270 colored squares. The text of the question along with the display of risks using the boxed diagram is given in Figure 1c. If they selected incorrectly, then the survey text explained their mistake. If they answered correctly, the survey text reinforced why their choice was correct ${ }^{11}$

Table 1 presents the experimental design used for this survey and illustrates how the attributes are constrained to be consistent with the features of each plan. The experimental design exploits a commonly used algorithm to construct near-optimal experimental designs. In our case, the selection was constrained to assure the assignment of attributes for each choice alternative was consistent with the features of the plan that was supposed to "deliver" the changes. In addition, we allowed for two different types of home test kits to allow greater variation in the testing time component of that plans approach to reducing the risk of food borne illness. This design evlauation led to twenty-four pairs of policy options. Designs were evaluated based on D-efficiency, which minimizes the geometric mean of the covariance matrix of the parameters and is the most commonly used criterion for constructing experimental designs. To reduce respondent burden, the trade-off tasks were blocked into twelve sets

${ }^{11}$ As Table 2 indicates five percent of the sample missed this question. 
of two questions. ${ }^{12}$ Each subject was randomly assigned to receive one of the twelve sets of two conjoint questions.

\section{Survey}

The survey was sent to the Knowledge Netowork panelists on August 24, 2007, and continued until September 10, 2007. The survey was sent to 2,242 panelists aged 18 and over. By the close of the survey 1,606 had completed the survey with a $72 \%$ completion rate.

Respondents were randomly assigned to the two versions of the food safety conjoint questions, resulting in a sample size of 801 respondents to the choice format with two plans and a status quo or no change alternative. The first column of Table 2 reports summary statistics for the demographic and economic attributes of this sample, including a measure of respondents' willingness to accept financial risks. The risk tolerance measure was derived using a framework developed by Barsky et. al. [1997]. Their index uses responses to questions about choices between a secure job for life and another with a 50-50 chance of two different income levels. With locally constant relative risk aversion, the answers classify respondents into one of four risk tolerance groups. ${ }^{13}$ We use the numerical scores they assign to each group. We also included questions about respondents' experiences with cases of sickness due to food as well as their experiences directly (or through someone they knew) with a hospitalization due to

\footnotetext{
${ }^{12}$ Two recent papers (Lusk and Norwood [2005] and Ferrini and Scarpa [2007]) have considered the properties of conjoint/discrete choice estimates with alternative experimental designs and specification errors. While neither study is directly relevant to our application - because they do not impose constraints on the design alternatives to meet pre-defined consistency features of a set of labeled choice alternatives - the Ferrini and Scarpa analysis considers the widest range of design alternatives and specification issues. Their conclusion seems quite relevant to our case. They note in the absence of detailed a priori information about the range of values for attributes and constraints on sample sizes then selecting rudimentary designs that are optimized for linear models is likely the best strategy (see p. 358-359).

${ }^{13}$ The formulation of the Barsky et. al. [1997] questions allows each respondent to be placed in intervals based on their response to an initial question and a follow up that changes the rewards up or down based on whether they accepted or rejected the initial offer. Their risk tolerance index, $\theta$, is the reciprocal of the coefficient of relative risk aversion. If $\mathrm{U}(\mathrm{y})$ is the utility function expressed in terms of annual income, $y$, then $1 / \theta=$ coefficient of relative risk aversion $=-y\left(U_{y y} / U_{y}\right)$.
} 
a case of food borne illness. Concerns about avian flu were asked to gauge respondent's perceptions of the prospects for conventional transmission of serious disease outbreaks across borders. We also asked about their smoking habits and whether the respondent was the primary food shopper. Knowledge Networks provided information from a client profile on a variety of health and food consumption questions. Income was elicited using household income in an interval format. The mid-point of each interval assigned to each respondent. A Pareto tail adjustment was used to set the value for the income assigned to those in the highest, open-ended interval (see Miller [1966]).

We also obtained from the Knowledge Networks profile data the full demographic and economic attributes of the non-respondents, panelists who were invited to take the survey but did not by the time it closed. The second column of Table 2 reports a probit model testing for whether KN panelists' demographic and economic characteristics affected their willingness to complete this survey. Age, race and whether the respondent was the primary shopper for their household are important determinants of participation. Panelists identifying themselves as black were less likely to take the survey, while panelists identifying themselves as white were more likely to participate. Primary shoppers were also less likely to participate. We have developed a simple but approximate strategy for accounting for this selection effect. We report the results with a selection term included but omitting it does not change the primary results from our analysis.

\section{Results}

\section{A. Choice Models}

Table 3 reports three choice models. The first two specifications include the total cost of each plan (tax cost plus product specific costs at annual level assuming purchases based on full utilization), the time required to use the test kit, alternative specific constants for each plan and an interaction term multiplying the time needed to use the kit with the inverse Mills ratio from our selection model given in 
the second column of Table $2^{14}$. Our hypothesis is that those panelists sensitive to the time requirements of a plan to test for food borne pathogens will also be sensitive to the time required to complete internet surveys. As we expect, the individuals who are less sensitive to time requirements are more likely to be a part of the sample and would respond to the KN invitation to participate sooner.

Models (1) and (2) are distinguished by the sample used. Model (1) includes all the respondents. Each person received two conjoint questions, described in the survey as independent situations, generating two observations for each respondent. We use a robust covariance estimator to account for the potential heteroscedasticity due to this panel feature of the sample and to take account of the fact that our approximate strategy for dealing with selection effects introduces heteroscedasticity.

Respondents consistently distinguish between the alternative plans - consumers have a clear

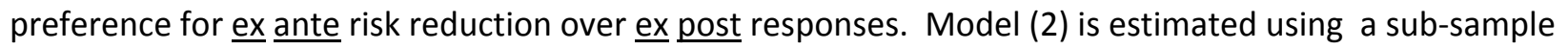
that deletes respondents who, at the outset of the survey, had difficulty correctly identifying the low risk situation using the box diagram to explain risk. The results are virtually indistinguishable comparing the estimated coefficients and the tests of the influence of the labels for the plans on the respondent's choices. Whether we include or do not include respondents who appeared initially unable to understand the graphical approaches used to describe risks did not affect these overall conclusions. Thus, it appears that at the simplest level the strategy to use specific plans that consumers accept as credible objects of choice seems to overcome some of the issues identified by Shogren and Stamlund. One of the most surprising, and seemingly counter intuitive result with these simple models, is the negative and significant coefficient for the plan to offer a medicine to reduce the severity of a case of food borne illness. This result reflects a preference for ex ante approaches. The plan with medicine does nothing to reduce risks and is likely to be interpreted by respondents as relying on personal action that

\footnotetext{
${ }^{14}$ These annualized costs were included in the choice panels presented to respondents.
} 
identifies the have contracted a food borne illness and then takes action to mitigate the symptoms of that illness at an early stage.

Model (3) in Table 3 reports a detailed specification for the choice model that includes both the alternative specific constants for the plans and the measures of the attributes. The interaction effects introduce nonlinearities in the effects of the attributes that mitigate the effects of the design induced collinearity between the attributes and the alternative specific constants used to define the plans' effects. For the risk change, we consider whether the measure of risk tolerance defined earlier, and elicited through a separate set of questions, influences the contribution of the risk change to choice. For the change in severity of the illness we use qualitative variables for respondents who rate their health as excellent or poor. For each plan variable, we include interactions that identify respondents who have had food borne illness, who know (or experienced) a case severe enough to be hospitalized, who indicate they are very or somewhat concerned about the spread of disease through a pandemic, and finally who indicate that they smoke.

Overall, we found a number of significant interaction effects indicating that respondent's characteristics, past experience, and information can influence the intensity of their preferences for avoiding illness. Most of the signs of the interaction effects are consistent with our a priori expectations and some are statistically significant using conventional criteria. Considering the parameter for severity, the coefficient reflecting the direct effect has a positive sign. But for respondents who rate their health to be excellent the coefficient on severity is negative (adding together the coefficients on severity and on the interaction term), while it is positive for those who rate their health as poor. The severity of the illness only varies under the medication plan, so individuals who consider their own health to be excellent are less likely to select the medication plan. Those who rate their health as poor seem willing to consider an ex post response with the medicine. While not statistically significant, the sign of the interaction of the risk change with the risk tolerance measure is consistent with a priori expectations. 
That is, those respondents who appear more willing to deal with risk will not pay as much for policies to reduce the risk of food borne illness.

The interaction terms between the alternative specific variables identifying the plans and individual attributes also are consistent with a priori expectations. Those with experience with food borne illness are more willing to purchase plans to increase inspectors. If they have been hospitalized or know someone who has, they are more likely to select the test to reduce their personal risk. Concerns about pandemics generally increases support for all plans. The only result that seems implausible is smoker's willingness to purchase the medicine. This term may be serving as a proxy for greater risk tolerance.

Thus, the detailed model generally confirms the external consistency by providing the links between most behaviors, health status, risk tolerance, prior information, risk perceptions, and stated choices. The Shogren-Stamlund "disconnect" does not appear to have affected our plan-based strategy for recovering choice information. However, it is harder to judge the tradeoff measures implied by these choices because some plans bundle multiple cost and attribute changes in ways that do not allow them to be separated. We turn to this issue in what follows.

B. Marginal Willingness to Pay Estimates-Basic Models

Table 4 reports the estimates for the marginal willingness to pay for each plan using only the alternative specific constants. ${ }^{15}$ Thus, they offer a basis for comparing only the plans. They rely on assuming comparable risk reductions and no "time costs" for using the test kits. Column (1)

\footnotetext{
${ }^{15}$ One could define a willingness to pay by considering a set of versions of each plan and deriving willingness to pay based on the log sum rule that results from considering a simple RUM with the type I extreme value error. However, this process would require us to define the set of choice alternatives. Since it would include specification of both the tax increases and the prices for the private good (i.e. test kit and medicine) alternatives and the time requirements the derived WTP would account for how differences in these aspects of plans influence the WTP. Unfortunately there is no policy relevant process to define the choice set and, thus, we must consider the simpler approximation we use in the construction of Tables 4 and 5.
} 
corresponds to estimates from model (1) and column (2) is model (2). The estimates for the plans for the private test kit and the increased inspections are not significantly different using a Wald test with the robust covariance matrix for the McFadden [1974] conditional logit model (model $(1) \chi^{2}(1)=1.14, p$ value $=0.286$, model $(2) \chi^{2}(1)=0.95, p$-value $\left.=0.329\right)$.

A "negative" marginal willingness to pay for the plan to offer a medicine to reduce the severity of illness simply reflects respondents' dissatisfaction with solutions focused exclusively on the ex post outcome. These estimates suggest the measures are not significantly different from zero. In short, consumers would not vote for this type of plan. The measures for opportunity cost of the time in food preparation may seem large $-\$ 22.50$ and $\$ 37.70$ per minute. However, the framing of the question is in terms of minutes for each time the test kit for food borne pathogens is used in preparing food that involves fresh vegetables and meats. It would not have been plausible to present it in another format, such as an annual time commitment because that would be based on assumptions about how many meals are prepared with fresh foods at home. As a result, it is then difficult to compare these estimates with other measures of the value of time. To do so requires knowledge of the expected patterns of use of the kits. These usage levels could easily be in the hundreds of occasions. For example, adding a minute to each of 150 meals would imply a value of 0.15 per minute (using our estimate of $\$ 22.50$ per minute) or an opportunity cost of time of about $\$ 9.00$ per hour and $\$ 15.00$ per hour with the $\$ 37.70$ estimate.

Before turning to some further cross checks of the framework using sub-samples, it is important to acknowledge that the food test kit implies a commitment beyond the income tax that depends on a discretionary choice. That is, a vote for the private plan for the test kit requires only a commitment to pay the proposed tax cost. It does not actually require respondents to buy the kit. A future purchase is always an option that respondents can assume they might make provided they have voted to assure the plan with food test kits is supported. This is why we argued some fraction of the proposed cost of the 
kit should be added to the marginal willingness to pay. This expected expenditure would reflect how frequently the consumer would anticipate purchasing the kit. Of course, the risk reduction proposed would not be realized without its use. Our description makes this point clear. Nonetheless, the equality of marginal willingness to pay for the two ex ante plans relies on using only the estimated parameters for alternative specific constants and the parameter for total cost term. While we do not know respondents' expectations for their expenditure patterns, it would seem that these consumers have a strong preference for the private plan to reduce risk.

\section{Marginal Willingness to Pay-Selected Respondents}

Table 5 reports the estimates of marginal willingness to pay for three sub-samples. We limit the sample to respondents who correctly answered the risk graphic question and then consider respondents who: (a) report they experienced food borne illness, (b) state they are the primary shopper, and (c) indicate on a 1 to 10 scale values of 5 or greater as likelihood results from their stated choices would influence policy (following Landry and List's [2006] to focus on respondents who consider their answers to be consequential). The marginal willingness to pay estimates for all three groups are somewhat larger as we expected. They are greatly different from the estimates based on the full sample with either the public or private plans for risk reductions, and, due to sample size, would not be judged significantly different from zero. However, this later result should be discounted because the estimated parameters are completely consistent with results from the full sample. With larger sub-samples these asymptotic results would have been consistent with our overall findings. We report them here as a consistency check-indicating the choice patterns displayed by those with attributes likely to feel food 
safety was important (e.g. those who have experienced illness and those who report they are the primary shopper). Equally important, if we narrow the focus to respondents who are likely to offer the most reliable tradeoffs using Landry and List's consequentiality index, we confirm the approximate size of the MWTP found for the full sample.

\section{Implications}

Consumers are clearly willing to pay to improve food safety and they are especially interested in reducing the risk of food borne disease. If given the opportunity to select how public policy makers would improve the safety of the food supply, households prefer strategies that offer them private control over the ways risks are reduced even if that entails some increased financial and time costs.

The concerns raised by other authors about the ability to elicit reliable measures for people's risk perceptions and behavioral choices do not seem to be present with our survey. The contradictory responses leading to Shogren and Stamland's concerns about disconnects between risk perceptions and behavior as threats to the external validity of estimated tradeoffs for risk reductions were not present in our survey. Presenting "labeled" choice alternatives that describe specific plans to reduce risk seem to have enhanced the perceived salience of the tasks involved. Nonetheless, this strategy does limit our ability to estimate the willingness to pay for cases of food borne illness. This arises because only one plan, the case of the public plan to increase food inspections, offers a reduction in risk paid for exclusively by an increase in the income tax. Using the marginal willingness to pay for this alternative (based on the alternative specific constant) and the range of risk reductions assigned for our design to this plan, yields a willingness to pay for an avoided case of food borne illness of $\$ 630$ to $\$ 963$ with the 
variation depending on the risk reduction matched to the estimate of the constant marginal willingness to pay for the plan. At its highest value this is one tenth the large estimates reported by Hammitt and Haninger. However, the range for our estimates is more consistent with both earlier food safety research and estimates of willingness to pay for short term morbidity effects in other contexts.

Two potentially important next steps in research stem from our findings. The first arises from the difficulties in covering separate estimates for the economic value of a reduction in risk of food borne illness with our approach when that reduction can be realized with a wide variety of different plans. It would be interesting to compare our approach maintaining the specialized design linking attributes to labeled plans to a more traditional conjoint where the choice alternatives share a common set of attributes and a single, plausible plan is used to describe how they would be brought about. This comparison would help to understand the implications of using plan/attribute combinations to recover marginal values for changes in attributes versus using the estimated parameters from a conventional conjoint model. This comparison may well extend beyond situations involving risk changes to a wider range of stated choice conjoint surveys. Surveys using labeled choice alternatives and comparing them with those the attribute based studies for comparable situations would help to enhance our understanding of the relevance of the the choice context for the performance of these models ${ }^{16}$. Our results suggest that this approach may be partially responsible for the anomalies in conjoint surveys involving risks. Second and directly relevant to the safety and security of the US food supply, it would seem that policy makers have neglected policies that provide for private production of food safety through in-home mitigation and testing. Our findings suggest strategies to address food safety need to be expanded to offer consumers private mitigation alternatives that can complement the existing

\footnotetext{
${ }^{16}$ This proposal is consistent with Berheim and Rangel's [2008] description of ancillary conditions. This is a feature of the choice environment that may affect behavior but is not taken to be relevant to the social planner's choice once the decision rests with that person. In our framework the context refers to aspects of the respondents' perceptions about ability of the proposed agency to deliver what is promised. It also relates to their familiarity with the payment terms. As discussed in Smith [2007] analysts assume people have full experience and that their decisions reflect the choice resolution required to measure consistent economic tradeoffs.
} 
protection from FDA's food inspection program rather than pre-supposing the preferred alternative is always focusing on increasing the federal inspection programs to provide a "public" good - uniform (and potentially smaller) risk reductions for all consumers. 


\section{REFERENCES}

Barsky, Robert B., F. Thomas Juster, Miles S. Kimball, and Matthew D. Shapiro, 1997, "Preference Parameters and Behavioral Heterogeneity: An Experimental Approach in the Health and Retirement Study," Quarterly Journal of Economics, Vol. 112 (May): 537-580.

Bernheim, B. Douglas and Antonio Rangel, 2008, “Beyond Revealed Preference: Choice Theoretic Foundations for Behavioral Economics", NBER working paper No. 13737, January.

Berrens, Robert P., Alok K. Bohara, Hank Jenkins-Smith, Carol Silva, and David L. Weimer, 2003, "The Advent of Internet Surveys for Political Research: A Comparison of Telephone and Internet Samples," Political Analysis, Vol. 11(1): 1-22.

Cameron, Trudy A. and J.R. DeShazo, 2005, “Comprehensive Selectivity Assessment for a Major Consumer Panel: Attitudes Toward Government Regulation of Environment, Health, and Safety Risks," unpublished paper, Department of Economics, University of Oregon, November.

Carson, Richard T. and W. Michael Hanemann, 2005, "Contingent Valuation" in Karl Göran-Mäler and Jeffrey R. Vincent editors, Handbook of Environmental Economics, Vol. II (Amsterdam: North Holland), pp. 821-936.

Carson, Richard T., Robert C. Mitchell, Michael Hanemann, Raymond J. Kopp, Stanley Presser, and Paul Ruud, 2003, “Contingent Vlaution and Lost Passive Use: Damages from the Exxon Valdez Oil Spill" Environmental and Resource Economics, Vol. 25 (July):257-286. 
Diamond, Peter A. and Jerry A. Hausman, 1994, "Contingent Valuation: Is Some Number Better than No Number?," Journal of Economic Perspectives, Vol. 8 (Fall): 45-64.

Florax, Raymond J.G.M., Chiara M. Travisi, and Peter Nijkamp, 2005, “A Meta Analysis of the Willingness to Pay for Reductions in Pesticide Risk Exposure," European Review of Agricultural Economics, Vol. 32(4), pp. 441-467.

Ferrini, Silvia and Riccardo Scarpa, 2007, “Designs with a priori Information for Non-Market Valuation with Choice Experiments: A Monte Carlo Study," Journal of Environmental Economics and Management, Vol. 53 (May): 342-363.

Hammitt, James K. and Kevin Haninger, 2007, “Willingness to Pay for Food Safety: Sensitivity to Duration and Severity," American Journal of Agricultural Economics, Vol. 89(5): 1170-1175.

Hayes,, Dermot, Jason Shogren, S. Shien, and J. Kliebenstein, 1995, "Valuing Food Safety in Experimental Auction Markets", American Journal of Agricultural Economics, Vol. 77 (1):40-53.

Holmes, Thomas P. and Viktor L. Adamowicz, 2003, "Attribute-Based Models," in P.A. Champ, K.J. Boyle, and T.C. Brown, editors, A Primer on Non-Market Valuation, (Dordrecht: Kluwer Academic), pp. 221-258. 
Johnson, F. Reed, Barbara J. Kanninen, Matthew Bingham, Semra Özdemir, 2007, “Experimental Design for Stated Choice Studies," B.J. Kanninen editor, Valuing Environmental Amenities Using Stated Choice Studies, (Dordrecht, The Netherlands: Springer) pp 297-333.

Landry, Craig E. and John A. List, 2007, “Using Ex Ante Approaches to Obtain Credible Signals for Value in Contingent Markets: Evidence from the Field," American Journal of Agricultural Economics, Vol. 89 (May): 420-429.

Lusk, Jayson L. and F. Bailey Norwood, 2005, "Effect of Experimental Design on Choice-Based Conjoint Valuation Estimates," American Journal of Agricultural Economics, Vol. 87 (August): 771-785.

McFadden, Daniel, 1974, "Conditional Logit Analysis of Qualitative Choice Behavior," in P. Zarembka editor, Frontiers of Econometrics (New York: Academic Press), pp. 105-142.

Miller, Herman P. 1966, Income Distribution in the United States, (A 1960 census monograph). Washington, D.C.: U.S. Government Printing Office.

Shogren, Jason F. and Tommy Stamland, 2007, “Valuing Lives Saved From Safer Food: A Contrary Tale Revisited," American Journal of Agricultural Economics, Vol. 89(5): 1176-1182.

Smith, V. Kerry, 1997, "Pricing What is Priceless: A Status Report on Non-Market Valuation of Environmental Resources," in Henk Folmer and Tom Tietenberg, editors, The International Yearbook of Environmental and Resource Economics (Cheltenham, U.K.: Edward Elgar), pp. 156204. 
Smith, V. Kerry. 2007, "Judging Quality," B.J. Kanninen editor, Valuing Environmental Amenities Using Stated Choice Studies, (Dordrecht, The Netherlands: Springer), pp. 297-333.

Train, Kenneth E., 2003, Discrete Choice Methods with Simulation, (Cambridge: Cambridge University Press).

U.S. Environmental Protection Agency, 1999, The Budget and Costs of the Clean Air Act 1990 to 2010 , EPA Report to Congress, Office of Air and Radiation, EPA-410-R-99-001, November. 
Figure 1a: Description of the Plans

\section{Improving Food Safety}

Now we want to ask you about some policies designed to reduce your risk of getting a food borne illness. Recently, there have been cases in the news about people who got sick after eating both fresh produce, like lettuce and spinach, and from meats and fish.

The government is considering several new policies that could reduce your risk of getting a food borne illness. Each potential policy would require additional resources to support federal activities in protecting the safety of our food supply from both domestic sources and international suppliers. Providing these added resources will require an increase in your income taxes of approximately $\$ 35.00$ per year indefinitely.

Below we describe some of the plans and ask you to tell us which plan you prefer.

We would like you to think about the following two plans:

\section{Hire more inspectors}

This plan would use the tax revenues from the increase to your taxes of $\$ 35.00$ to increase the budget for the Food and Drug Administration (the FDA). By hiring more inspectors, the risk that you will get a food borne illness will be lower. The inspections will not change the amount of time you are sick if you do get sick.

- The FDA will use the money to hire more inspectors.

- The inspectors will focus on preventing fresh fruits and vegetables and meat produced in the U.S. and food imported from other countries from being contaminated with the most common food borne bacteria and pathogens. 


\section{Purchase medicine}

This plan would use the tax revenues from the increase of $\$ 35.00$ to your taxes to subsidize the costs of a medicine that you can take if you get a food borne illness. Although the medicine does not change the risk that you would get a food borne illness, it will shorten the amount of time your are sick.

- The medicine is good for food borne illnesses caused by the most common food borne bacteria and pathogens in fresh fruits and vegetables and meat. The medicine causes very mild side effects, but no serious or lasting side effects.

- This medicine will be available without a prescription, but you have to order it ahead of time from the pharmacy and delivery takes several weeks. You need to have the medicine on hand -- you will not have time to order it once you got sick.

- After 1 year the medicine expires and will no longer work, so you need to buy more medicine each year.

\section{Home test kit}

This plan would use the tax revenues from the increase in your taxes of $\$ 35.00$ to subsidize the costs of a home test kit that would allow you and your family to test all of your food. By testing your food, the possibility that you would become sick would be reduced (your risk of getting a food borne illness would be lower). Testing will not change the amount of time you are sick if you do get sick.

- When you answer this question, please assume the results from tests with these kits would be very reliable. You can test fresh fruits and vegetables and meat for the most common food borne bacteria and pathogens.

- Raw food is tested before cooking using the kit. This means that preparing a meal will take longer.

- If the test is positive and the food contains bacteria, the only way to completely protect yourself and your family would be to throw the food away without eating it.

- After 1 year, the test kit materials expire and the test no longer works. So each year, you will have to buy a new kit. 
Figure 1b: Choice Panel for the Food Safety Survey

Remember that the plans will require an increase in your taxes and possibly an additional cost specific to the plan, as displayed in the table below.

In previous similar surveys people often responded to a survey in one way but if they actually faced the decision they acted differently. It is particularly common to find that people are more willing to say they will pay for something or vote for something and then with an actual choice they do not. One reason for these differences is that these people have not fully considered the impact an extra cost would have on the family budget.

When you answer this question, please think about the cost of the plans, including the increase in your taxes.

\begin{tabular}{|c|c|c|c|}
\hline & Current Situation & $\begin{array}{l}\text { Hire more } \\
\text { inspectors }\end{array}$ & $\begin{array}{l}\text { Purchase } \\
\text { medicine }\end{array}$ \\
\hline $\begin{array}{l}\text { Annual risk of food } \\
\text { borne illness }\end{array}$ & $\begin{array}{l}27 \% \\
270 \text { in } 1000 \text { people } \\
\text { get sick each year }\end{array}$ & $\begin{array}{c}1 \% \\
10 \text { in } 1,000 \text { people } \\
\text { get sick each year }\end{array}$ & $\begin{array}{c}27 \% \\
270 \text { in } 1,000 \text { people } \\
\text { get sick each year }\end{array}$ \\
\hline $\begin{array}{c}\text { Average amount of } \\
\text { time you will be } \\
\text { sick }\end{array}$ & 48 hours & 48 hours & 24 hours \\
\hline $\begin{array}{l}\text { Extra time needed } \\
\text { to prepare food }\end{array}$ & No added time & No added time & No added time \\
\hline Cost & No added cost & No added cost & $\begin{array}{l}\$ 5 \text { per year or about } \\
\$ 0.42 \text { per month }\end{array}$ \\
\hline $\begin{array}{l}\text { Annual increase in } \\
\text { income taxes }\end{array}$ & No added cost & $\$ 35.00$ & $\$ 35.00$ \\
\hline Your vote & 0 & 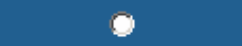 & 0 \\
\hline
\end{tabular}


Figure 1c: Explanation of Risk Changes Using Relative Frequency Box and Question to Evaluate Respondent Understanding of Risk

Later in the survey, we will ask you to consider plans to reduce the risk of food borne illness. The 3 boxes below are to help you imagine different risks of getting a food borne illness that we will describe later in the survey. Box A represents the current risk, while Box B and Box C are lower risks associated with some of the plans we will describe.

Each box has 1000 squares and each square represents one person. The shaded squares represent people who get a food borne illness and the unshaded squares represent people who do not get a food borne illness.

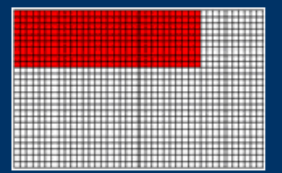

Box A: Current risk of food borne illness, $27 \%$ or 270 people out of 1,000 get sick

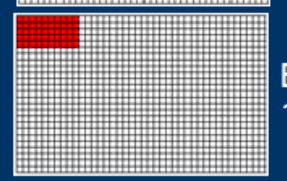

Box B: Risk of $5 \%$ or 50 people out of 1,000 get sick

Box C: Risk of $1 \%$ or 10 people out of

1,000 get sick

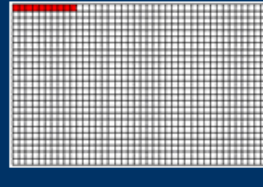

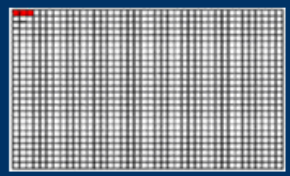

Box D

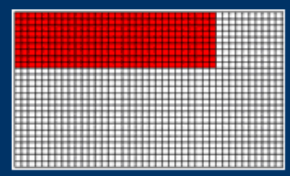

Box A

Does Box $D$ show a situation with a higher risk of getting sick or a lower risk than Box A above (which displays the current risk of $27 \%)$ ?

Select one answer only

- Box D shows a higher risk of getting sick

- Box D shows a lower risk of getting sick 
Table 1: Experimental Design for Safety of the Food Supply ${ }^{a}$

\begin{tabular}{|c|c|c|c|c|c|c|c|c|c|c|}
\hline \multirow{2}{*}{$\begin{array}{c}\text { Design No. } \\
\text { Tax Amount }= \\
\$ 35\end{array}$} & \multicolumn{5}{|c|}{ First Question } & \multicolumn{5}{|c|}{ Second Question } \\
\hline & Plan & Risk & Cost & Severity & Time & Plan & Risk & Cost & Severity & Time \\
\hline \multirow[t]{2}{*}{1} & Insp & 10 & 0 & 48 & 0 & Med & 270 & 40 & 12 & 0 \\
\hline & Med & 270 & 5 & 24 & 0 & Insp & 10 & 0 & 48 & 0 \\
\hline \multirow[t]{2}{*}{2} & Insp & 10 & 0 & 48 & 0 & Kit2 & 10 & 10 & 48 & 5 \\
\hline & Med & 270 & 40 & 3 & 0 & Kit1 & 50 & 40 & 48 & 10 \\
\hline \multirow[t]{2}{*}{3} & Insp & 50 & 0 & 48 & 0 & Kit2 & 50 & 40 & 48 & 5 \\
\hline & Med & 270 & 40 & 24 & 0 & Med & 270 & 40 & 24 & 0 \\
\hline \multirow[t]{2}{*}{4} & Kit2 & 100 & 40 & 48 & 10 & Kit1 & 100 & 40 & 48 & 10 \\
\hline & Med & 270 & 10 & 3 & 0 & Med & 270 & 5 & 24 & 0 \\
\hline \multirow[t]{2}{*}{5} & Insp & 50 & 0 & 48 & 0 & Kit2 & 10 & 5 & 48 & 5 \\
\hline & Med & 270 & 5 & 12 & 0 & Insp & 100 & 0 & 48 & 0 \\
\hline \multirow[t]{2}{*}{6} & Insp & 100 & 0 & 48 & 0 & Insp & 100 & 0 & 48 & 0 \\
\hline & Kit1 & 50 & 5 & 48 & 5 & Kit2 & 10 & 10 & 48 & 5 \\
\hline \multirow[t]{2}{*}{7} & Insp & 10 & 0 & 48 & 0 & Kit2 & 100 & 10 & 48 & 10 \\
\hline & Med & 270 & 10 & 3 & 0 & Med & 270 & 10 & 12 & 0 \\
\hline \multicolumn{11}{|l|}{$\begin{array}{c}\text { Tax Amount }= \\
\$ 50\end{array}$} \\
\hline \multirow[t]{2}{*}{8} & Kit1 & 10 & 5 & 48 & 5 & Ins & 50 & 0 & 48 & 10 \\
\hline & Insp & 50 & 0 & 48 & 0 & Med & 270 & 5 & 12 & 0 \\
\hline \multirow[t]{2}{*}{9} & Kit1 & 10 & 40 & 48 & 10 & Kit1 & 100 & 5 & 48 & 10 \\
\hline & Med & 270 & 5 & 24 & 0 & Med & 270 & 40 & 3 & 0 \\
\hline \multirow[t]{2}{*}{10} & Kit2 & 100 & 40 & 48 & 10 & Kit1 & 50 & 10 & 48 & 10 \\
\hline & Med & 270 & 10 & 3 & 0 & Kit1 & 100 & 40 & 48 & 5 \\
\hline \multirow[t]{2}{*}{11} & Kit2 & 100 & 10 & 48 & 10 & Kit1 & 50 & 10 & 48 & 5 \\
\hline & Med & 270 & 40 & 24 & 0 & Kit2 & 10 & 40 & 48 & 10 \\
\hline \multirow[t]{2}{*}{12} & Kit2 & 10 & 5 & 48 & 5 & Kit2 & 50 & 5 & 48 & 5 \\
\hline & Insp & 100 & 0 & 48 & 0 & Insp & 100 & 0 & 48 & 0 \\
\hline
\end{tabular}

${ }^{\mathrm{a}}$ The design values in the table correspond to different units for each variable: risk it is cases in 1000 of individuals experiencing food borne illness in a year. Thus 270 is 270 cases in 1000 people. Cost is the annual cost for each plan that is in addition to the increased taxes. Severity is the duration of the illness in hours for an average case of food borne illness. Time is the added minutes for food preparation each time the home test kit is used. The abbreviations for the plans are: kit corresponds to the home test kit for presence of bacteria or pathogens; med refers to the proposed medicine that would reduce the severity of a case of food borne illness, and insp. refers to plan to increase the number of FDA inspectors to evaluate food products for bacteria or pathogens. 
Table 2: Characteristics and Selection Model KN for Food Safety Sample ${ }^{a}$

\begin{tabular}{|c|c|c|}
\hline $\begin{array}{c}\text { Sample } \\
\text { Characteristics }\end{array}$ & $\begin{array}{c}\text { Means and } \\
\text { Standard } \\
\text { Deviation }\end{array}$ & $\begin{array}{l}\text { Probit Selection } \\
\text { Model }^{\mathrm{b}}\end{array}$ \\
\hline \multirow[t]{2}{*}{ Household Income } & 54,006 & $.043 \times 10^{-5}$ \\
\hline & $(42,593)$ & $(0.64)$ \\
\hline \multirow[t]{2}{*}{ Age } & 48.0 & .016 \\
\hline & (16.9) & (8.89) \\
\hline \multirow[t]{2}{*}{ Proportion Female } & 0.53 & -.039 \\
\hline & $(0.50)$ & $(-0.72)$ \\
\hline \multirow[t]{2}{*}{ Proportion White } & 0.75 & .238 \\
\hline & $(0.43)$ & (3.49) \\
\hline \multirow[t]{2}{*}{ Proportion Black } & & -.227 \\
\hline & & $(-2.38)$ \\
\hline \multirow[t]{2}{*}{ Proportion Own Home } & 0.71 & .046 \\
\hline & $(0.45)$ & $(0.74)$ \\
\hline \multirow[t]{2}{*}{ Unemployed } & & -.001 \\
\hline & & $(0.00)$ \\
\hline \multirow[t]{2}{*}{ Risk Tolerance } & 0.36 & \\
\hline & $(0.48)$ & \\
\hline \multirow[t]{2}{*}{ Proportion Retired } & 0.18 & \\
\hline & $(0.39)$ & \\
\hline \multirow[t]{2}{*}{ Proportion HS Grad } & 0.33 & \\
\hline & $(0.47)$ & \\
\hline Proportion & 0.17 & .110 \\
\hline College Grad & $(0.37)$ & $(1.45)$ \\
\hline Personally Experienced & .57 & \\
\hline Food Borne Illness & $(.49)$ & \\
\hline Hospitalized with Food & .21 & \\
\hline Borne Illness & $(.41)$ & \\
\hline \multicolumn{3}{|l|}{ Proportion Concerned } \\
\hline about Pandemics with & .45 & \\
\hline Avian Flu (Very or & $(.50)$ & \\
\hline \multicolumn{3}{|l|}{ Somewhat Concerned) } \\
\hline Proportion Missed & .05 & \\
\hline Risk Question & $(.21)$ & \\
\hline \multirow[t]{2}{*}{ Proportion Smoke } & .10 & \\
\hline & $(.31)$ & \\
\hline Proportion Primary & .66 & \\
\hline Shopper & $(.47)$ & \\
\hline \multirow[t]{2}{*}{ Intercept } & & -.440 \\
\hline & & $(-4.39)$ \\
\hline $\begin{array}{l}\text { Number of } \\
\text { Observations }\end{array}$ & 801 & 2415 \\
\hline Pseudo $\mathrm{R}^{2}$ & & .0519 \\
\hline
\end{tabular}

${ }^{a}$ The numbers in parentheses are the standard deviations.

${ }^{\mathrm{b}}$ The numbers in parentheses below the estimated coefficients are the Z-statistics for the null hypothesis of no association of each determinant with the decision of a KN panelist to complete the survey. 
Table 3: Detailed Choice Model for the Security of the Food Supply ${ }^{a}$

\begin{tabular}{|c|c|c|c|}
\hline Independent Variable & $(1)$ & $(2)$ & $(3)$ \\
\hline Tax + product cost & $\begin{array}{l}.0044 \\
(-1.68) \\
\end{array}$ & $\begin{array}{l}-0047 \\
(-1.77) \\
\end{array}$ & $\begin{array}{r}-.0033 \\
(-1.10) \\
\end{array}$ \\
\hline \multicolumn{4}{|l|}{ Charge in Risk } \\
\hline Coef & & & $\begin{array}{l}.0029 \\
(2.38)\end{array}$ \\
\hline Coef * Rtol & & & $\begin{array}{r}-.0008 \\
(-1.20) \\
\end{array}$ \\
\hline \multicolumn{4}{|l|}{ Severity } \\
\hline Coef & & & $\begin{array}{l}.0216 \\
(1.99) \\
\end{array}$ \\
\hline Coef * health excellent & & & $\begin{array}{r}-.0312 \\
(-2.24) \\
\end{array}$ \\
\hline Coef * health poor & & & $\begin{array}{l}.0294 \\
(1.45) \\
\end{array}$ \\
\hline \multicolumn{4}{|l|}{ Test Kit (= 1) } \\
\hline Coef & $\begin{array}{l}.9231 \\
(4.88)\end{array}$ & $\begin{array}{l}.9181 \\
(4.73) \\
\end{array}$ & $\begin{array}{r}-.3591 \\
(-1.00) \\
\end{array}$ \\
\hline Coef * Exp illness & & & $\begin{array}{r}-.0263 \\
(-0.15) \\
\end{array}$ \\
\hline Coef * Pandemic & & & $\begin{array}{r}.9560 \\
(5.49) \\
\end{array}$ \\
\hline Coef $*$ Smoke & & & $\begin{array}{l}.4057 \\
(1.44) \\
\end{array}$ \\
\hline Coef * Know Hospital & & & $\begin{array}{l}.5688 \\
(2.79)\end{array}$ \\
\hline \multicolumn{4}{|l|}{ Medicine $(=1)$} \\
\hline Coef & $\begin{array}{l}-.5791 \\
(-3.24) \\
\end{array}$ & $\begin{array}{l}-.5553 \\
(-3.02) \\
\end{array}$ & $\begin{array}{r}-2.0798 \\
(-4.36)\end{array}$ \\
\hline Coef * Exp illness & & & $\begin{array}{l}.3453 \\
(1.58)\end{array}$ \\
\hline Coef $*$ Smoke & & & $\begin{array}{l}.7972 \\
(2.56) \\
\end{array}$ \\
\hline Coef * Pandemic & & & $\begin{array}{r}1.0847 \\
(5.07)\end{array}$ \\
\hline Coef * Know Hospital & & & $\begin{array}{c}.223 \\
(0.89) \\
\end{array}$ \\
\hline \multicolumn{4}{|l|}{ Inspectors (= 1) } \\
\hline Coef & $\begin{array}{l}.7152 \\
(5.39)\end{array}$ & $\begin{array}{l}.7369 \\
(5.41) \\
\end{array}$ & $\begin{array}{c}-4191 \\
(-1.25) \\
\end{array}$ \\
\hline Coef * Exp illness & & & $\begin{array}{l}.4312 \\
(2.42) \\
\end{array}$ \\
\hline Coef * Pandemic & & & $\begin{array}{l}.8397 \\
(4.67)\end{array}$ \\
\hline Coef $*$ Smoke & & & $\begin{array}{l}-.0142 \\
(-0.05) \\
\end{array}$ \\
\hline Coef * Know Hospital & & & $\begin{array}{c}.2504 \\
(-1.15)\end{array}$ \\
\hline Time & $\begin{array}{l}-.1850 \\
(-5.88)\end{array}$ & $\begin{array}{l}-.1775 \\
(-5.51)\end{array}$ & $\begin{array}{l}-.1569 \\
(-4.40)\end{array}$ \\
\hline Time * Mills & $\begin{array}{l}.1618 \\
(3.42) \\
\end{array}$ & $\begin{array}{l}.1611 \\
(3.17)\end{array}$ & $\begin{array}{l}.1282 \\
(2.24)\end{array}$ \\
\hline Pseudo $\mathrm{R}^{2}$ & .066 & .066 & .109 \\
\hline
\end{tabular}

${ }^{a}$ Numbers in parentheses are asymptotic $Z$ statistics for null hypothesis of no association; sample restricted to respondents who correctly answer risk comparison question. 
Table 4: Estimated Marginal Willingness to Pay for Food ${ }^{a}$

\begin{tabular}{|lcc|}
\hline \multicolumn{1}{|c|}{ Plans } & $(1)$ & $(2)$ \\
\hline Test Kit & 211.3 & 195.2 \\
& $(1.99)$ & $(2.11)$ \\
\hline Food Inspectors & 163.7 & 156.6 \\
& $(2.21)$ & $(2.35)$ \\
\hline Medicine & -132.6 & -118.0 \\
& $(-1.14)$ & $(-1.15)$ \\
\hline Opportunity cost of & 22.5 & 37.7 \\
time & $(1.47)$ & $(1.60)$ \\
\hline
\end{tabular}

${ }^{a}$ The numbers in parentheses are the asymptotic $Z$ statistics for a test of zero marginal willingness to pay. 
Table 5: Marginal Willingness to Pay Estimates for Food Safety Sub-Samples for Different Consumer Groups ${ }^{a}$

\begin{tabular}{|cccc|}
\hline & $\begin{array}{c}\text { Experience Food } \\
\text { Borne Illness }\end{array}$ & $\begin{array}{c}\text { Primary Food } \\
\text { Shopper }\end{array}$ & $\begin{array}{c}\text { Consider the } \\
\text { Survey } \\
\text { Consequential }\end{array}$ \\
\hline Plan Models & & & \\
\hline Test Kit & 241.1 & 256.6 & 253.2 \\
& $(1.06)$ & $(1.05)$ & $(1.33)$ \\
\hline Food Inspectors & 259.1 & 211.6 & 256.4 \\
& $(1.09)$ & $(1.12)$ & $(1.39)$ \\
\hline Medicine & -154.1 & -227.7 & -50.3 \\
& $(-0.66)$ & $(-0.71)$ & $(-0.51)$ \\
\hline Opportunity Cost of & 27.4 & 29.5 & 19.5 \\
Time & $(0.82)$ & $(0.82)$ & $(0.97)$ \\
\hline
\end{tabular}

${ }^{a}$ Numbers in parentheses are asymptotic $Z$ statistics for null hypothesis of zero marginal willingness to pay. 